\title{
Correction to: Is Patlak y-intercept a relevant metrics?
}

\author{
Eric Laffon ${ }^{1,2,3,4}$ (D) $\cdot$ Roger Marthan ${ }^{1,2,3}$
}

Published online: 26 February 2021

(C) Springer-Verlag GmbH Germany, part of Springer Nature 2021

\section{Correction to: Eur J Nucl Med Mol Imaging https://doi.org/10.1007/s00259-020-04954-0}

There was some mistakes in the original article that needs to be fixed by doing the following:

Introduction: " $K_{i}$ parametric imaging" should be changed to " $\mathrm{K}_{\mathrm{i}}$-parametric imaging".

Theory: exponentially decreasing functions in Eqs. 1, 2, 4 and 6 have been erroneously written with two minus signs instead of one (as in Eq. 5).

Results: the part of the sentence “... the steady-state uptakerate constant $K_{\mathrm{i}}$ of the tissue of interest (more precisely, (1$\left.V_{b}\right) \times K_{\mathrm{i}}$ ) can be estimated as ..." should be changed to "... the steady-state uptake-rate constant $K_{\mathrm{i}}$ of the tissue of interest (more precisely, $\left.\left(1-V_{b}\right) \times K_{\mathrm{i}}\right)$ can be estimated as ..."

The original article has been corrected.

Publisher's note Springer Nature remains neutral with regard to jurisdictional claims in published maps and institutional affiliations.

This article is part of the Topical Collection on Erratum

The online version of the original article can be found at https://doi.org/ 10.1007/s00259-020-04954-0

Eric Laffon

elaffon@u-bordeaux.fr

1 CHU de Bordeaux, 33000 Bordeaux, France

2 Centre de Recherche Cardio-Thoracique de Bordeaux, University of Bordeaux, 33000 Bordeaux, France

3 Centre de Recherche Cardio-Thoracique de Bordeaux, INSERM U-1045, 33000 Bordeaux, France

4 Service de Médecine Nucléaire, Hôpital du Haut-Lévèque, Avenue de Magellan, 33604 Pessac, France 